\title{
Updates on the treatment of adhesive capsulitis with hydraulic distension
}

\section{Jang Hyuk Cho}

Department of Rehabilitation Medicine, Keimyung University Dongsan Medical Center, Keimyung University School of Medicine, Daegu, Korea

Received: June 30, 2020

Revised: August 8, 2020

Accepted: August 10, 2020

Corresponding authors:

Jang Hyuk Cho

Department of Rehabilitation

Medicine, Keimyung University

Dongsan Medical Center, Keimyung

University School of Medicine, 1095

Dalgubeol-daero, Dalseo-gu, Daegu

42601, Korea

Tel: +82-53-258-7912

Fax: +82-53-258-7130

E-mail: jangcho@kmu.ac.kr
Adhesive capsulitis of the shoulder joint is a common disease characterized by pain at the insertional area of the deltoid muscle and decreased range of motion. The pathophysiological process involves fibrous inflammation of the capsule and intraarticular adhesion of synovial folds leading to capsular thickening and contracture. Regarding the multidirectional limitation of motion, a limitation in external rotation is especially prominent, which is related to not only global fibrosis but also to a localized tightness of the anterior capsule. Ultrasound and magnetic resonance imaging studies can be applied to rule out other structural lesions in the diagnosis of adhesive capsulitis. Hydraulic distension of the shoulder joint capsule provides pain relief and an immediate improvement in range of motion by directly expanding the capsule along with the infusion of steroids. However, the optimal technique for hydraulic distension is still a matter of controversy, with regards to the infusion volume and rupture of the capsule. By monitoring the real-time pressure-volume profile during hydraulic distension, the largest possible fluid volume can be infused without rupturing the capsule. The improvement in clinical outcomes is shown to be greater in capsule-preserved hydraulic distension than in capsule-ruptured distension. Moreover, repeated distension is possible, which provides additional clinical improvement. Capsule-preserved hydraulic distension with maximal volume is suggested to be an efficacious treatment option for persistent adhesive capsulitis.

Keywords: Inflammation; Joint capsule; Pain; Shoulder joint

\section{Introduction}

Adhesive capsulitis is a disease that presents with pain due to inflammation of the joint capsule, which progresses to fibrosis and hypertrophy, and gradually causes joint contracture of the shoulder $[1,2]$. Clinical findings are the most important for diagnosis, and plain radiography should be normal [3]. Recently, ultrasound and magnetic resonance imaging (MRI) have also been commonly used for accurate diagnosis. For treatment based on the pathogenesis, it is important to reduce inflammation and improve flexibility of the joint capsule. Conservative treatments-including medication, physical therapy, and exercise- - to alleviate pain and restore range of motion (ROM) are generally considered before surgical treatment [4]. However, these managements require persistent and active treatment, and it can take a long time to show improvements [5]. Hydraulic distension, which is a more aggressive treatment, is an interventional procedure in which a sufficient amount of fluid is injected into the stiff shoulder capsule. Hydraulic distension is used clinically for adhesive capsulitis to reduce inflammation of the joint capsule and directly relieve contracture, alleviate pain, and improve ROM [6]. Although there have been many reports on the clinical effects of hydraulic distension, there is still no standardized distension method [7]. In this review, we aim to discuss the clinical presentation of adhesive capsulitis, the principles

Copyright (C) 2021 Yeungnam University College of Medicine

This is an Open Access article distributed under the terms of the Creative Commons Attribution Non-Commercial License (http://creativecommons.org/licenses/by-nc/4.0/) which permits unrestricted non-commercial use, distribution, and reproduction in any medium, provided the original work is properly cited. 
and trends of hydraulic distension as a therapeutic intervention.

\section{The clinical presentation of adhesive capsulitis}

Adhesive capsulitis is characterized by shoulder pain and gradually decreasing shoulder ROM [1]. In 1896, Duplay defined periarthritis as reduced ROM due capsular fibrosis; in 1934, Codman defined frozen shoulder as slowly progressing shoulder pain and reduced ROM without abnormal radiographic findings; and in 1945, Neviaser defined adhesive capsulitis caused pathologically by inflammation and fibrosis [2]. Various other names have also been used, including pericapsulitis and painful stiff shoulder $[1,8]$.

Adhesive capsulitis affects $2 \%$ to $10 \%$ of the population, is more prevalent in women, and the age of onset is usually around 40 to 69 years (average, 55 years) [9]. The nondominant side is more commonly affected; however, $20 \%$ to $30 \%$ of patients are bilaterally affected and recurrence in the same shoulder is known to be relatively rare [10-12]. Adhesive capsulitis occurs more frequently in patients with endocrine diseases, such as diabetes mellitus or thyroid disease, or autoimmune disease; in particular, diabetes mellitus patients show an increased prevalence of up to $20 \%[13,14]$. It has been rarely reported to be associated with hyperlipidemia $[15,16]$. Predisposing factors include long-term immobility after trauma or surgery, calcific tendinitis, rotator cuff tear, and glenohumeral or acromioclavicular arthritis [17].

In order to diagnose adhesive capsulitis, plain radiography findings should be normal, though there may be accompanying osteopenia. Plain radiography is useful for differentiation from other diseases causing acute pain and reduced ROM [3]. The MRI and ultrasound to differentiate accompanying diseases, such as calcific tendinitis, rotator cuff tear, or bursitis, is not directly required but can help with diagnosis. Generally, clinical diagnosis through physical examination is the most important.

Pathological findings include reactive fibrosis and contracture of the joint capsule due to synovial inflammation, capsular and synovial adhesions, and dense capsular hypertrophy; these findings are most severe in the axillary recess and may progress as far as the attachment to the anatomical neck of the humerus [10,18-21]. According to recent research, joint capsules with reduced ROM are accompanied by not only global fibroplasia but also localized contracture of rotator cuff interval and the coracohumeral ligament [22]. This may be related to the clinical characteristic wherein external rotation shows the most severe decrease in ROM. The coracohumeral ligament is a target structure of stretching exercises and is an important pathological structure in adhesive capsulitis [23]. In addition, this could be the basis for why surgical treatment produces good outcomes even when only performed on the anterior part of the joint capsule [22].

The course of the disease can be divided into four stages depending on pain, duration of illness, arthroscopic findings, and pathologic appearance [18-20]. Stage 1 is the preadhesion and inflammation stage, pertaining to the first 3 months, in which severe pain is mostly experienced at night at the attachment of the deltoid muscle, but the shoulder ROM is preserved. Arthroscopy shows synovial inflammation and there are pathological findings of hypervascular synovitis. Stage 2 is the freezing stage, occurring at around 3 to 9 months, in which there is severe pain and progression of reduced ROM. Arthroscopy shows proliferative synovitis and adhesions, and there are pathological appearances of hypervascular synovitis, fibrous proliferation, and scarring. Stage 3 is the frozen stage, at 9 to 15 months, in which pain gradually decreases and is experienced at the ends of the ROM, but there is a severe decrease in ROM. In arthroscopy, hypervascularity is no longer observed, but there is hypertrophy of the joint capsule and loss of the axillary fold. Pathological findings include burned-out synovitis and dense hypercellular scarring. Stage 4 is the thawing stage, pertaining to 15 to 24 months, in which there is almost no pain and joint ROM gradually improves. Arthroscopy shows capsular scarring and mature adhesions. There have been no reports of the pathological appearance at this stage (Table 1) [18-20]. However, staging of adhesive capsulitis is difficult to implement, because it does not always fit well with the clinical symptoms. According to a recent study, $27.7 \%$ of patients with chronic adhesive capsulitis persisting for more than 2 years are not satisfied with the state of their shoulders [5]. In addition, it may be difficult to perform the arthroscopic and pathological examinations only required to determine the disease stage. Therefore, adhesive capsulitis can be considered a chronic disease that requires active treatment from the initial stages.

\section{Treatment approaches to adhesive capsulitis}

Adhesive capsulitis presents with pain due to inflammation of the joint capsule, progressing to fibrosis and hypertrophy, and gradually causing joint contracture. Therefore, the aims of treatment are to relieve pain by reducing inflammation and restoring joint ROM. General conservative treatments consist of physical therapy, exercise, nonsteroidal anti-inflammatory drugs, and intraarticular steroid injections. Interventional procedures include hydraulic distension and manipulation under anesthesia. Surgical procedures include arthroscopic capsular release and open capsulotomy. Because the inflammatory reaction causes fibrosis of the synovium, 
Table 1. Stages of adhesive capsulitis [18-20]

\begin{tabular}{|c|c|c|c|c|}
\hline \multirow{2}{*}{ Variable } & \multicolumn{4}{|c|}{ Stage } \\
\hline & 1 (Preadhesive) & 2 (Freezing) & 3 (Frozen) & 4 (Thawing) \\
\hline Duration (mo) & $0-3$ & $3-9$ & $9-15$ & $15-24$ \\
\hline Symptoms and signs & $\begin{array}{l}\text { Painful shoulder movement } \\
\text { Minimal restriction in motion } \\
\text { Pain referred to deltoid insertion }\end{array}$ & $\begin{array}{l}\text { Painful shoulder movement } \\
\text { Progressive loss of joint } \\
\text { motion } \\
\text { Stiffness }\end{array}$ & $\begin{array}{l}\text { Reduced pain with shoulder } \\
\text { movement } \\
\text { Severely restricted joint motion } \\
\text { Stiffness }\end{array}$ & $\begin{array}{l}\text { Progressive improvement of } \\
\text { joint motion } \\
\text { Pain minimal }\end{array}$ \\
\hline Arthroscopic appearance & $\begin{array}{l}\text { Fibrinous synovial inflammatory } \\
\text { reaction } \\
\text { No adhesions or capsular } \\
\text { contracture }\end{array}$ & $\begin{array}{l}\text { Diffuse, thickened and prolif- } \\
\text { erative synovitis } \\
\text { Adhesion formation in the } \\
\text { axillary fold extending to } \\
\text { the humeral head }\end{array}$ & $\begin{array}{l}\text { Loss of axillary fold } \\
\text { Diminished capsular volume } \\
\text { No hypervascularity } \\
\text { Minimal synovitis with matura- } \\
\text { tion }\end{array}$ & $\begin{array}{l}\text { Fully mature adhesions } \\
\text { Capsular scar }\end{array}$ \\
\hline Pathologic findings & $\begin{array}{l}\text { Hypervascular, hypertrophic } \\
\text { synovitis } \\
\text { Normal capsular tissue }\end{array}$ & $\begin{array}{l}\text { Hypervascular, hypertrophic } \\
\text { synovitis } \\
\text { Fibroplasia and perivascular } \\
\text { scar formation }\end{array}$ & $\begin{array}{l}\text { Hypercellular, dense and collage- } \\
\text { nous tissue with a thin synovial } \\
\text { membrane similar to other fi- } \\
\text { brosing conditions } \\
\text { Extensive fibroplasia } \\
\text { "Burned out" synovitis } \\
\text { Scar formation }\end{array}$ & Not reported \\
\hline
\end{tabular}

anti-inflammatory treatment is essential to improve symptoms and prevent fibrosis; therefore, intraarticular steroid injections, which have a strong anti-inflammatory action, are effective [4].

Clinically, decisions regarding treatment can be aided by dividing the course of the disease into stage 1 , in which there is severe pain due to inflammation but ROM is preserved; stage 2 , in which there is progression of inflammation and joint capsule fibrosis leading to pain and reduced ROM; and stage 3, in which inflammation recedes and fibrosis peaks, leading to improved pain and worsening ROM. Stage 1 patients show considerable improvement with conservative treatment, including intraarticular steroid injections. In stage 2 patients, the disease often cannot be managed with conservative treatment alone, and interventional procedures also need to be considered [24]. In other words, in the stage where inflammation is the main problem, inflammation needs to be treated. In the stage when joint contracture caused by fibrosis is the main problem, treatment to stretch and improve flexibility in the thickened and contracted joint capsule is more appropriate. In patients who do not show a sufficient response to conservative treatment and require interventional procedures, hydraulic distension is used, which requires injecting a sufficient volume of fluid consisting of a mixture of local anesthetic and normal saline into the intraarticular space [6]. During the common treatment for adhesive capsulitis based on the current knowledge, hydraulic distension is performed while injecting intraarticular steroids, and rehabilitation including exercise is performed to restore shoulder ROM [7]. Manipulation under anesthesia has been reported to be an effective intervention to improve pain and joint ROM [25]. However, the procedure can cause injuries such as fractures near the humeral neck and rotator cuff tears and may have a risk involved in the use of general anesthesia $[26,27]$. Surgical release is usually performed at the anterior part of the capsule, were local contracture is observed pathologically [22]. Arthroscopic capsule release can be attempted in patients with diabetes when manipulation under anesthesia has failed, but the cases when it is required are limited [27-29]. Open capsulotomy can rarely be attempted when capsular release fails $[30,31]$.

\section{Current trends in hydraulic distension}

\section{Therapeutic mechanisms of hydraulic distension}

Hydraulic distension, which was first reported in 1965 by Andren and Lundberg [32], is a procedure in which fluid is injected into the intraarticular space of the shoulder to expand the stiff joint capsule and eliminate adhesions that are limiting ROM. The injection of a large volume of fluid raises the intraarticular pressure, and at peak pressure, the joint capsule ruptures, eliminating adhesions and scar tissue, which is known to improve ROM [6,9,32-34]. According to current evidence, hydraulic distension has a superior effect in the treatment of adhesive capsulitis compared to other general conservative treatments. Hydraulic distension with steroids plus physical therapy was superior to physical therapy alone in the functional improvement of adhesive capsulitis [35].

In a study comparing a group of patients that received only hydraulic distension, a group that received only intraarticular steroid injection, and a group that received hydraulic distension and intraarticular steroids simultaneously, the improvement in joint 
ROM was greatest in the group that received both hydraulic distension and steroids [36]. Thus, hydraulic distension alongside intraarticular steroids allowed not only the dose of analgesics to be reduced but also a significant improvement in ROM compared to steroid injection alone. This demonstrates that, when performing hydraulic distension, injecting steroids with the fluids is far more effective [6]. Incorporating hydraulic distension with steroids could improve the effectiveness of intraarticular steroid injection in the treatment of the adhesive capsulitis [37].

The reported adverse effects of hydraulic distension are afterpains, loss of sensation and motor control in the affected arm, flushing, nausea, dizziness, and syncope $[38,39]$. These were rated as mild and brief, with complete spontaneous resolution [38]. Another important point is that the clinicians need to be concerned with an adverse effect like glenohumeral joint infection [40].

In order to obtain a distension effect, a high pressure needs to be created by injecting fluid into the stiff joint capsule. Previous studies have used very diverse fluid volumes, from 2 to $150 \mathrm{~mL}$, and demonstrated different effects of the procedure according to capsule rupture or preservation [9]. In freezing stage patients, hydraulic distension causing capsule rupture without the use of steroids was reported to increase joint ROM, providing evidence that capsule-ruptured hydraulic distension can produce favorable effects despite thus use of no steroids [33]. Meanwhile, one recent study reported that capsule-ruptured hydraulic distension with steroids should be considered as the first treatment for adhesive capsulitis [7]. However, capsule rupture after hydraulic distension occurs most frequently in the subscapular fossa and sometimes in the subacromial-subdeltoid bursa and the long head of biceps tendon sheath, rather than in the anterior capsule and rotator cuff interval; these sites are where adhesive capsulitis originates and are responsible for the reduced ROM $[41,42]$. These capsule-rupturing regions do not show increased intraarticular stiffness and do not contain rotator cuff attachments. In addition, the joint capsule in these regions is weak and thin, with a thickness of less than $1 \mathrm{~mm}[9,34,41,42]$. During capsule-rupturing hydraulic distension, the intraarticular steroids leak into the surrounding soft tissues, which can cause adverse effects such as atrophy of adipose tissue, weakening of tendons and ligaments, and changes in skin pigmentation [43].

Hydraulic distension is not yet standardized and continually developing. Previously, hydraulic distension was mostly performed using arthrography; ultrasound-guided hydraulic distension has become more common in recent years as ultrasound devices have advanced. Capsule-preserving hydraulic distension, in which the intraarticular pressure is measured during fluid injection to prevent capsule rupture in real-time, is more effective than capsule-ruptur- ing hydraulic distension [44-49].

\section{Capsule-preserving hydraulic distension}

Capsule-preserving hydraulic distension is performed per the protocol described below [45-47]. The skin is properly disinfected, with the subject in a seated position. A disposable pressure sensor and a 3.5-inch 22-gauge needle connected to the hydraulic distension device are placed in the posterior shoulder capsule under ultrasound guidance. The hydraulic distension device is used to inject $49 \mathrm{~mL}$ of $0.5 \%$ lidocaine solution and $40 \mathrm{mg}$ of triamcinolone ( $50 \mathrm{~mL}$ total) into the intraarticular space at a constant rate of 5 $\mathrm{mL} /$ minute. While injecting the solution, the intraarticular pressure is monitored in real-time. In order to ensure preservation of the joint capsule, ultrasound is used to check that the injection solution is expanding the joint capsule and remaining in the intraarticular space without leakage (Fig. 1) [46,48].

Some previous studies have reported that capsule-rupturing hydraulic distension is better than capsule-preserving hydraulic distension; however, only a small volume of fluid $(2-10 \mathrm{~mL})$ was actually injected into the intraarticular space [36]. When hydraulic distension is performed while monitoring the intraarticular pressure, the mean capsule-preserving volume was reported to be $25.1 \pm 6.9 \mathrm{~mL}$ [49]. The joint capsule ruptures after a mean injected volume; therefore, the previous studies might not properly reflect the effects of capsule-preserving hydraulic distension.

In capsule-preserving hydraulic distension, the maximum volume fluid is injected at a constant rate without causing capsule rupture, and the intraarticular pressure is measured in real-time to preserve the fluid in the capsule for a long time. Monitoring reveals a pressure-volume curve with three phases: phase I (initial filling) shows a flat curve, phase II (elastic deformation) shows a steep linear increase in pressure, and phase III (plastic deformation) shows a shallow curve [44]. This is similar to the three phases of the stress-strain curve of soft tissue in response to extension [49]. When the fluid is injected, there is a flat curve of pressure in phase I until the pressure rapidly rises in phase II and the slope of the steep curve increases, and then, after a sufficient volume has been injected, the curve becomes shallow in phase III; immediately after this, a sudden loss of pressure is observed, indicating capsule rupture (Fig. 2) [45,49]. For this reason, in order to obtain the maximum distension effect, fluid injection should be stopped at the start phase III, which occurs immediately before capsule rupture. 'Pre-rupture signs' were verified to be when phase III of the pressure-volume curve is observed, or the intraarticular pressure exceeds $500 \mathrm{mmHg}[46,47]$. The mean capsule-preserving volume of hydraulic distension in adhesive capsulitis patients was reported to be $25.1 \pm 6.9 \mathrm{~mL}$ therefore, the smallest volume for effective 

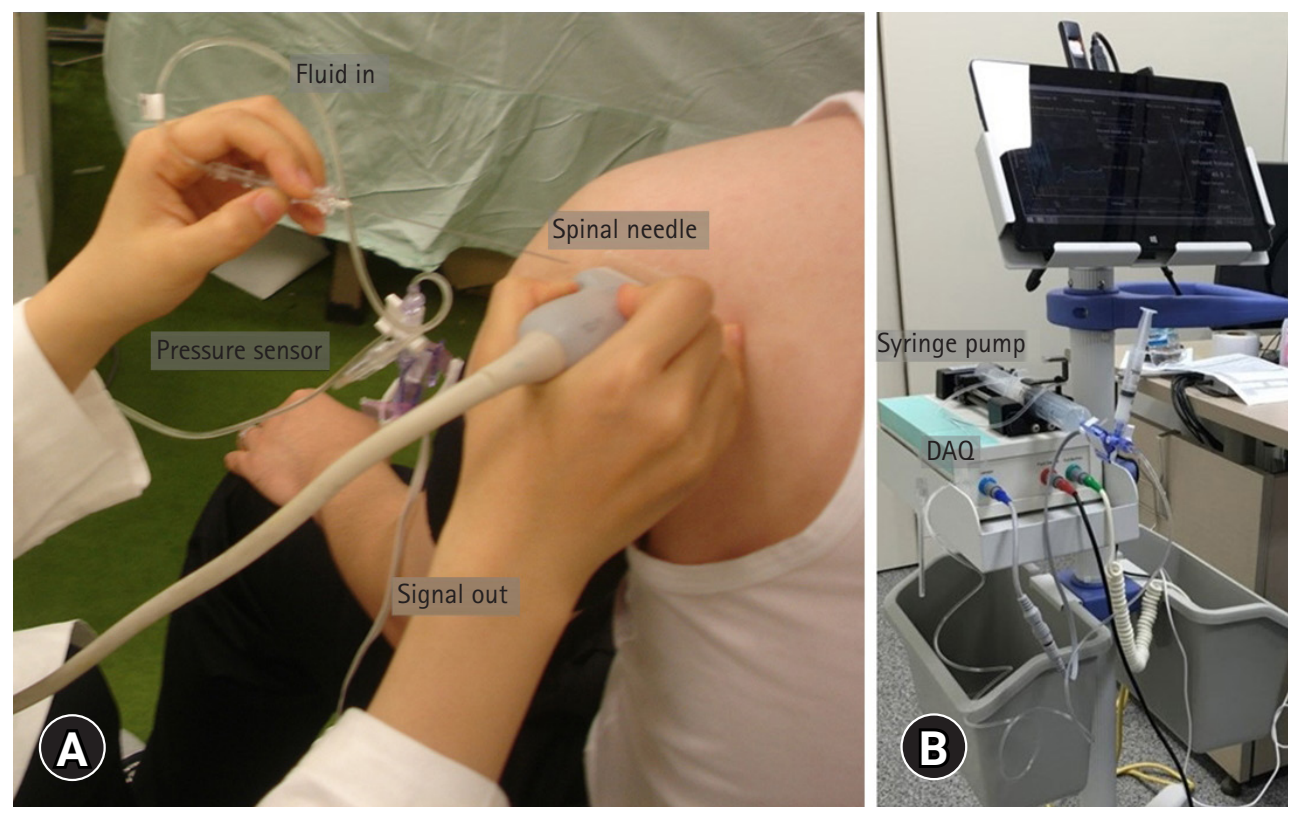

Fig. 1. Experimental setup for capsule-preserved hydraulic distension (A) with real-time pressure monitoring (B). While the patient is comfortably seated upright on a stool, a 3.5-inch 22-gauge spinal needle is inserted $1 \mathrm{~cm}$ lateral to the ultrasound transducer and advanced into the posterior intraarticular space under ultrasound guidance. The pressure sensor is connected to manometric tubes via a 3-way stopcock so that the pressure in the tubes can be measured by the sensor while fluid is infused via the syringe pump. The signal from the sensor is digitalized by a data-acquisition device (DAO).

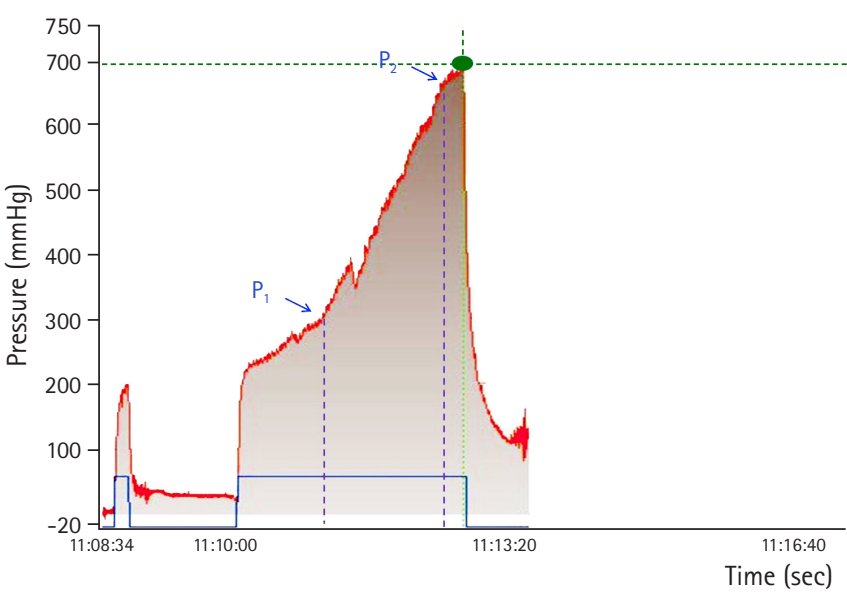

Fig. 2. Typical pressure-volume curve obtained during intraarticular hydraulic distension. The slope of the phase II (from $P_{1}$ to $P_{2}$ ) is considered the capsular stiffness phase. $P_{1}$, pressure at the starting point of phase $\mathrm{II}_{;} \mathrm{P}_{2}$, pressure at the ending point of phase II.

capsule-preserving hydraulic distension is suggested to be approximately $18 \mathrm{~mL}$ [49]. In the case of real-time pressure monitoring of intraarticular hydraulic distension is not available, hydraulic distension using a total fluid volume of $18 \mathrm{~mL}$ under ultrasound guidance to ensure preservation of the joint capsule may be effective.

It is important to stop fluid injection immediately before capsule rupture. To this end, a real-time pressure-volume profile monitor- ing system is used to measure the intraarticular pressure, predict the time of capsule rupture, and stop fluid injection immediately before rupture. A sufficient volume of fluid needs to be injected and maintained in capsule for as long as possible without rupture in order to produce a large treatment effect. Moreover, the intraarticular steroids can be retained within the intraarticular space for a long time without leakage, resulting in better inflammation control $[46,49]$.

The effects of stretching are observed when a prolonged constant tension, which is enough to induce plastic elongation of the shortening tissue, is applied [50]. In the case of adhesive capsulitis, continuous stretching of the contracted connective tissue is possible when a large volume of fluid is injected into the intraarticular space and it maintain expansion of the adhered capsule without causing rupture [47]. Conversely, if fluid is injected until the capsule ruptures, although it is possible to deliver the greatest load, this effect may disappear immediately after rupture. Following rupture, the intraarticular pressure drops rapidly as the injected solution leaks outside of the capsule. It then becomes difficult to stretch and expand the adhered capsule, and the treatment effect may decrease. When clinical improvements in pain and joint ROM were evaluated, compared to capsule rupture, injecting the maximum volume while preserving the joint capsule resulted in superior effects [46].

Hydraulic distension with steroids can be repeated in the case of 
failure or unsatisfactory results from a single hydraulic distension, and repeated procedures are more effective for pain alleviation than a single procedure [51]. When the hydraulic pressure causes capsule rupture during repeated distension, the intraarticular fluid leaked through the previously rupture area, and the clinical effect was diminished. Furthermore, capsule-preserving hydraulic distension with steroids showed a greater improvement after repeated procedures [47]. In order to investigate the effects of repeated hydraulic distension in adhesive capsulitis patients, a study performed three capsule-preserving distension procedures at 1-month intervals $[47,51]$. Following the second repeated procedure, there were significant improvements in the outcomes of not only biomechanical factors, such as reduced capsule stiffness and increased capacity, but also clinical outcomes, with increased ROM and reduced pain. Since biomechanical changes in the contracted joint capsule were accompanied by improvements in the clinical indices of ROM and pain, repeated capsule-preserving hydraulic distension can be considered a very useful treatment method for adhesive capsulitis $[47,51]$.

In adhesive capsulitis secondary to previous surgery or trauma, there may be stiffness due to outer adhesion of the rotator cuff. This also may be due to postoperative scarring or soft tissue injury. In particular, secondary adhesive capsulitis after fracture is less effective in hydraulic distension; it may be accompanied by a combination of capsule contractures and extraarticular adhesions [52]. Thus, further studies are needed to verify whether implementing repeated capsule-preserving hydraulic distension could produce better outcomes than conventional treatment methods, even for adhesive capsulitis patients with a poor prognosis or recurrent pain.

\section{Conclusion}

Treatments for adhesive capsulitis are available to reduce inflammation and improve flexibility of the joint capsule. Of these, hydraulic distension is an effective interventional procedure. Capsule-rupturing hydraulic distension is the method of rupturing the adhered capsule after injecting fluid under image guidance. However, the area that is actually ruptured, is not the area showing adhesions, but instead the subscapular fossa, which is a weak and thin area of the joint capsule. In capsule-preserving hydraulic distension, a real-time pressure-volume profile monitoring system is used to measure the intraarticular pressure while injecting the maximum volume of fluids immediately before capsule rupture. It can expand the adhered joint capsule for as long as possible by stretching the contracted tissue continuously. As the injected steroid can be retained within the intraarticular space for longer, this proce- dure is better at controlling inflammation and shows a superior treatment effect compared to capsule-rupturing hydraulic distension. Furthermore, considering the mean maximal capsule-preserving volume of hydraulic distension $(25.1 \pm 6.9 \mathrm{~mL})$, the smallest volume for effective capsule-preserving hydraulic distension is indicated to be approximately $18 \mathrm{~mL}$. Therefore, hydraulic distension using a total fluid volume of $18 \mathrm{~mL}$ with steroid under ultrasound guidance to ensure preservation of the joint capsule may be available. In conclusion, capsule-preserving hydraulic distension is a safe treatment method that can be used repeatedly. As a result, we believe that it will also be helpful for treating adhesive capsulitis patients who respond poorly to treatment or show recurrence.

\section{Acknowledgments}

\section{Conflicts of interest}

No potential conflict of interest relevant to this article was reported.

\section{Funding}

This research was supported by the Translational Research Program for Care Robots funded by the Ministry of Health \& Welfare, Republic of Korea (grant number: HK20C0007).

\section{Additional information}

The author would like to thank Keewon Kim, MD and Sun G. Chung, MD, Professors at Seoul National University, for their permission to use and publish their figures.

\section{ORCID}

Jang Hyuk Cho, https://orcid.org/0000-0001-7916-8428

\section{References}

1. Baslund B, Thomsen BS, Jensen EM. Frozen shoulder: current concepts. Scand J Rheumatol 1990;19:321-5.

2. Lewis J. Frozen shoulder contracture syndrome: aetiology, diagnosis and management. Man Ther 2015;20:2-9.

3. Binder AI, Bulgen DY, Hazleman BL, Tudor J, Wraight P. Frozen shoulder: an arthrographic and radionuclear scan assessment. Ann Rheum Dis 1984;43:365-9.

4. De Jong BA, Dahmen R, Hogeweg JA, Marti RK. Intra-articular triamcinolone acetonide injection in patients with capsulitis of the shoulder: a comparative study of two dose regimens. Clin Rehabil 1998;12:211-5.

5. Kim DH, Kim YS, Kim BS, Sung DH, Song KS, Cho CH. Is frozen shoulder completely resolved at 2 years after the onset of 
disease? J Orthop Sci 2020;25:224-8.

6. Gam AN, Schydlowsky P, Rossel I, Remvig L, Jensen EM. Treatment of "frozen shoulder" with distension and glucorticoid compared with glucorticoid alone: a randomised controlled trial. Scand J Rheumatol 1998;27:425-30.

7. Haughton DN, Barton S, Meenan E, Mehan R, Wykes P, Warner J, et al. Can we improve the outcome of hydrodilatation for adhesive capsulitis? Shoulder Elbow 2018;10:93-8.

8. Brue S, Valentin A, Forssblad M, Werner S, Mikkelsen C, Cerulli G. Idiopathic adhesive capsulitis of the shoulder: a review. Knee Surg Sports Traumatol Arthrosc 2007; 15:1048-54.

9. Buchbinder R, Green S, Forbes A, Hall S, Lawler G. Arthrographic joint distension with saline and steroid improves function and reduces pain in patients with painful stiff shoulder: results of a randomised, double blind, placebo controlled trial. Ann Rheum Dis 2004;63:302-9.

10. Rizk TE, Pinals RS. Frozen shoulder. Semin Arthritis Rheum 1982;11:440-52.

11. Hand GC, Athanasou NA, Matthews T, Carr AJ. The pathology of frozen shoulder.J Bone Joint Surg Br 2007;89:928-32.

12. Zuckerman JD, Rokito A. Frozen shoulder: a consensus definition. J Shoulder Elbow Surg 2011;20:322-5.

13. Pal B, Anderson J, Dick WC, Griffiths ID. Limitation of joint mobility and shoulder capsulitis in insulin- and non-insulin-dependent diabetes mellitus. Br J Rheumatol 1986;25:147-51.

14. Griggs SM, Ahn A, Green A. Idiopathic adhesive capsulitis: a prospective functional outcome study of nonoperative treatment. J Bone Joint Surg Am 2000;82:1398-407.

15. Wohlgethan JR. Frozen shoulder in hyperthyroidism. Arthritis Rheum 1987;30:936-9.

16. Lo SF, Chu SW, Muo CH, Meng NH, Chou LW, Huang WC, et al. Diabetes mellitus and accompanying hyperlipidemia are independent risk factors for adhesive capsulitis: a nationwide population-based cohort study (version 2). Rheumatol Int 2014;34:67-74.

17. Noel E, Thomas T, Schaeverbeke T, Thomas P, Bonjean M, Revel M. Frozen shoulder. Joint Bone Spine 2000;67:393-400.

18. Neviaser RJ, Neviaser TJ. The frozen shoulder: diagnosis and management. Clin Orthop Relat Res 1987;(223):59-64.

19. Hannafin JA, Chiaia TA. Adhesive capsulitis: a treatment approach. Clin Orthop Relat Res 2000;(372):95-109.

20. Neviaser AS, Hannafin JA. Adhesive capsulitis: a review of current treatment. Am J Sports Med 2010;38:2346-56.

21. Van Royen BJ, Pavlov PW. Treatment of frozen shoulder by distension and manipulation under local anaesthesia. Int Orthop 1996;20:207-10.

22. Uhthoff HK, Boileau P. Primary frozen shoulder: global capsu- lar stiffness versus localized contracture. Clin Orthop Relat Res 2007;456:79-84.

23. Baek S, Lee KJ, Kim K, Han SH, Lee UY, Lee KJ, et al. High-pressure balloon-assisted stretching of the coracohumeral ligament to determine the optimal stretching positions: a cadaveric study. PMR2016;8:925-34.

24. Marx RG, Malizia RW, Kenter K, Wickiewicz TL, Hannafin JA. Intra-articular corticosteroid injection for the treatment of idiopathic adhesive capsulitis of the shoulder. HSS J 2007;3:202-7.

25. Quraishi NA, Johnston P, Bayer J, Crowe M, Chakrabarti AJ. Thawing the frozen shoulder: a randomised trial comparing manipulation under anaesthesia with hydrodilatation. J Bone Joint Surg Br 2007;89:1197-200.

26. Dodenhoff RM, Levy O, Wilson A, Copeland SA. Manipulation under anesthesia for primary frozen shoulder: effect on early recovery and return to activity. J Shoulder Elbow Surg 2000; 9:23-6.

27. Khan MH, Nuhmani S. Frozen shoulder: a review of current concepts. J Musculoskelet Pain 2014;22:308-13.

28. Baums MH, Spahn G, Nozaki M, Steckel H, Schultz W, Klinger HM. Functional outcome and general health status in patients after arthroscopic release in adhesive capsulitis. Knee Surg Sports Traumatol Arthrosc 2007; 15:638-44.

29. Ogilvie-Harris DJ, Biggs DJ, Fitsialos DP, MacKay M. The resistant frozen shoulder: manipulation versus arthroscopic release. Clin Orthop Relat Res 1995; (319):238-48.

30. Fields BK, Skalski MR, Patel DB, White EA, Tomasian A, Gross JS, et al. Adhesive capsulitis: review of imaging findings, pathophysiology, clinical presentation, and treatment options. Skeletal Radiol 2019;48:1171-84.

31. Le HV, Lee SJ, Nazarian A, Rodriguez EK. Adhesive capsulitis of the shoulder: review of pathophysiology and current clinical treatments. Shoulder Elbow 2017;9:75-84.

32. Andren L, Lundberg BJ. Treatment of rigid shoulders by joint distension during arthrography. Acta Orthop Scand 1965;36: $45-53$.

33. Vad VB, Sakalkale D, Warren RF. The role of capsular distention in adhesive capsulitis. Arch Phys Med Rehabil 2003;84:12902.

34. Rizk TE, Gavant ML, Pinals RS. Treatment of adhesive capsulitis (frozen shoulder) with arthrographic capsular distension and rupture. Arch Phys Med Rehabil 1994;75:803-7.

35. Khan AA, Mowla A, Shakoor MA, Rahman MR. Arthrographic distension of the shoulder joint in the management of frozen shoulder. Mymensingh Med J 2005;14:67-70.

36. Jacobs LG, Barton MA, Wallace WA, Ferrousis J, Dunn NA, Bossingham DH. Intra-articular distension and steroids in the 
management of capsulitis of the shoulder. BMJ 1991;302: 1498-501.

37. Reza SS, Bijan F, Asghar HA, Morteza T. Treatment of frozen shoulder: a double blind study ccomparing the impact of triamcinolone injection alone or in association with joint distention. Res J Pharm Biol Chem Sci 2013;4:226-34.

38. Catapano M, Mittal N, Adamich J, Kumbhare D, Sangha H. Hydrodilatation with corticosteroid for the treatment of adhesive capsulitis: a systematic review. PM R 2018;10:623-35.

39. Saltychev M, Laimi K, Virolainen P, Fredericson M. Effectiveness of hydrodilatation in adhesive capsulitis of shoulder: a systematic review and meta-analysis. Scand J Surg 2018;107:28593.

40. Tveita EK, Tariq R, Sesseng S, Juel NG, Bautz-Holter E. Hydrodilatation, corticosteroids and adhesive capsulitis: a randomized controlled trial. BMC Musculoskelet Disord 2008; 9:53.

41. Clark J, Sidles JA, Matsen FA. The relationship of the glenohumeral joint capsule to the rotator cuff. Clin Orthop Relat Res 1990;(254):29-34.

42. Gavant ML, Rizk TE, Gold RE, Flick PA. Distention arthrography in the treatment of adhesive capsulitis of the shoulder. J Vasc Interv Radiol 1994;5:305-8.

43. Lussier A, Cividino AA, McFarlane CA, Olszynski WP, Potashner WJ, De Medicis R. Viscosupplementation with hylan for the treatment of osteoarthritis: findings from clinical practice in Canada. J Rheumatol 1996;23:1579-85.

44. Lee KJ, Lee HD, Chung SG. Real-time pressure monitoring of intraarticular hydraulic distension for painful stiff shoulders. J Orthop Res 2008;26:965-70.

45. Chung SG, Lee KJ, Kim HC, Seo KS, Lee YT. Intra-articular pressure profiles of painful stiff shoulders compared with those of other conditions. PM R 2009; 1:297-307.

46. Kim K, Lee KJ, Kim HC, Lee KJ, Kim DK, Chung SG. Capsule preservation improves short-term outcome of hydraulic distension in painful stiff shoulder. J Orthop Res 2011;29:1688-94.

47. Koh ES, Chung SG, Kim TU, Kim HC. Changes in biomechanical properties of glenohumeral joint capsules with adhesive capsulitis by repeated capsule-preserving hydraulic distensions with saline solution and corticosteroid. PM R 2012;4:976-84.

48. Yi Y, Lee KJ, Kim W, Oh BM, Chung SG. Biomechanical properties of the glenohumeral joint capsule in hemiplegic shoulder pain. Clin Biomech (Bristol, Avon) 2013;28:873-8.

49. Lee SY, Lee KJ, Kim W, Chung SG. Relationships between capsular stiffness and clinical features in adhesive capsulitis of the shoulder. PM R 2015;7:1226-34.

50. Kottke FJ, Pauley DL, Ptak RA. The rationale for prolonged stretching for correction of shortening of connective tissue. Arch Phys Med Rehabil 1966;47:345-52.

51. Piotte F, Gravel D, Moffet H, Fliszar E, Roy A, Nadeau S, et al. Effects of repeated distension arthrographies combined with a home exercise program among adults with idiopathic adhesive capsulitis of the shoulder. Am J Phys Med Rehabil 2004;83: 537-46.

52. Robinson CM, Seah KT, Chee YH, Hindle P, Murray IR. Frozen shoulder.J Bone Joint Surg Br 2012;94:1-9. 